\title{
A Novel Incentive Mechanism with Government Subsidy for the Key Technologies R\&D of New Energy Automobile Industry
}

\author{
Ru He, ${ }^{1}$ Chui-Yong Zheng, ${ }^{1}$ and Huan-Huan Zhao $\mathbb{D I D}^{2}$ \\ ${ }^{1}$ School of Business Hohai University, Nanjing 211100, China \\ ${ }^{2}$ School of Management Wuxi Institute of Technology, Wuxi 214121, Jiangsu Province, China \\ Correspondence should be addressed to Huan-Huan Zhao; huan983405544@163.com
}

Received 4 June 2021; Accepted 16 September 2021; Published 29 September 2021

Academic Editor: Josefa Mula

Copyright (c) $2021 \mathrm{Ru} \mathrm{He}$ et al. This is an open access article distributed under the Creative Commons Attribution License, which permits unrestricted use, distribution, and reproduction in any medium, provided the original work is properly cited.

The key technology research and development (R\&D) of new energy automobile industry is a collaborative innovation activity of multi-innovation subjects, and how to set up effective incentive mechanisms and safeguards to stimulate innovative subjects and urge them to invest in corresponding efforts is crucial to ensure the success of key technologies R\&D in the new energy automobile industry. To solve the incentive problem of key technology R\&D of new energy automobile industry, considering government subsidy and the risk attitude of government and innovation subject, from the perspective of stakeholder negotiation and system coordination, introduce the minimum-cost consensus method into grey target decision-making and set constraint conditions to ensure a stable and effective incentive method. Then use a case to verify the effectiveness and rationality of the proposed model.

\section{Introduction}

As the contradiction between crude oil supply and demand has gradually deepened, besides environmental pollution and global warming have become increasingly serious, "energy conservation and emission reduction" has gradually become the consensus of all countries in the world. Therefore, the development of new energy vehicles is inevitable. The development of the new energy industry is very important to improve a country's overall science and technology, industrialization level, and comprehensive national strength. The new energy industry is a strategic industry for all countries. In 2010, the State Council issued the "Decision on Accelerating the Cultivation and Development of Strategic Emerging Industries." The decision listed the new energy automobile industry and other industries as China's seven strategic emerging industries. In 2015, the "Made in China 2025" issued by the State Council proposed to continue to support the development of electric vehicles and fuel cell vehicles. It also proposed to form a complete industrial system and innovation system from key parts to complete vehicles. And it proposed to promote own brand energy-saving and new energy automobiles with the international advanced level and strengthen the use of intellectual property. In 2020, the General Office of the State Council issued the "New Energy Automobile Industry Development Plan (2021-2035)." The plan pointed out that China should break through the key core technology and optimize the industrial development environment. Through these ways, China could promote the high-quality sustainable development of China's new energy automobile industry, speeding up the time for China to become a powerful vehicle country. The plan also pointed out that new energy automobile industry had become a national strategy. The key technology of new energy automobile industry is an important part of supporting the development of new energy automobile industry, which is directly related to the promotion of industrial core competitiveness and the promotion of healthy and sustainable development of the industry $[1,2]$. The R\&D of key technologies in the new energy automobile industry involves innovative subjects, such as enterprises, research institutes, universities, consulting institutions, and financial institutions. How to ensure that the profits of innovative subjects are not damaged, mobilize the enthusiasm and initiative of each subjects, encourage them to invest more efforts and collaborations, and achieve the 
successful R\&D of key technologies in the industry has become an urgent problem to be solved in the development of the new energy automobile industry.

To deal with this problem, we establish a government subsidy incentive mechanism for key technology R\&D of new energy automobile industry. The contents of this paper are organized as follows. Section 2 is related to literature review. Section 3 shows the government subsidy incentive mechanism. Section 4 verifies the effectiveness and rationality of the proposed model. Section 5 concludes all model proposed in this paper and points out possible research directions in the future.

\section{Literature Review}

To realize $\mathrm{R} \& \mathrm{D}$ of the key technologies in the new energy automobile industry more effectively, the government often influences the behaviors of enterprises by giving certain funds to subsidize the innovation subject, starting from the whole industry development and social welfare and sustainable, rapid, and healthy development and then mobilizing the enthusiasm and initiative of innovation subject collaboration and R\&D [3-5]. Scholars at home and abroad mainly set up incentive strategies and mechanisms from three aspects to solve the problem of R\&D incentive under government subsidy: the influence of government subsidy on enterprise $\mathrm{R} \& \mathrm{D}$, the effect measurement and evaluation of government subsidy, and the choice of government subsidy strategy. (1) The influence and function of government subsidy on enterprise $\mathrm{R} \& \mathrm{D}$ is mainly reflected in the relationship between government subsidy and enterprise $\mathrm{R} \& \mathrm{D}$ incentive and enterprise $\mathrm{R} \& \mathrm{D}$ decision. Among them, Xie et al. [6] considered the risk characteristics of $\mathrm{R} \& \mathrm{D}$, analyzed the influence of government subsidies and venture capital on enterprise innovation incentives, and discussed the relationship between government subsidies and enterprise technology innovation incentives; differences in the nature of enterprise ownership may lead to differences in government subsidy strategies. Shang and Huang [7] and Sun et al. [8] studied the influence of government subsidies on the decision-making behavior of innovation subjects under different ownership properties. $\mathrm{Wu}$ [9] proposed that government subsidies have different R\&D behaviors for private enterprises and state-owned enterprises, and we should increase $R \& D$ subsidies for private enterprises. $\mathrm{Wu}$ et al. [10] found that from the perspective of information transmission, government subsidies play an important role in promoting technology innovation of enterprises in emerging industries. Peng and Liu [11] and Yu et al. [12] studied the impact of government subsidies in the field of renewable energy on the R\&D decision-making behavior of enterprises. Li et al. [13] studied the similarities and differences between government consumption subsidies and substitution subsidies in innovation subjects. (2) Considering the influence of government subsidies on enterprise innovation, some scholars try to measure the effect of government subsidies through statistical models and decision-making methods. Lin [14] used empirical data to test the impact of government $R \& D$ subsidies on SMEs' R\&D investment. The results show that government R\&D subsidies are significantly positively correlated with SMEs' R\&D investment. Peng and Wang [15] used OLS and PSM models to measure and analyze the policy effects of Chinese government innovation subsidies in the context of a transitional economy. Deng and $\mathrm{Wu}$ [16] considered technology spillover, social welfare level, and R\&D model. They discussed the incentive effect of government subsidy intensity on innovation subjects by constructing a three-stage dynamic game model. Söderblom et al. [17] and Bronzini and Piselli [18] used an improved multivariate regression model to analyze the impact of government subsidies on $\mathrm{R} \& \mathrm{D}$ investment and enterprise performance and enterprise innovation based on year data. Hong et al. [19] used the stochastic frontier model to analyze the effect of government subsidies in high-tech industries. From the perspective of temporal and spatial differentiation, Yang and Liu [20] used the evaluation method to comprehensively evaluate and measure the R\&D subsidies of high-tech industries in different time and space in China. (3) In order to adopt a more effective government subsidy strategy, some scholars analyze the effect and influence of different government subsidy strategies on technology R\&D incentives. First of all, government should select property R\&D project. Dong et al. [21] proposed an MAGDM method with incomplete attribute weight information to select property $\mathrm{R} \& \mathrm{D}$ project. The government adopts different preferential tax rates in different periods, which affects consumers' purchase intentions significantly [22, 23], which also has a significant positive impact on $R \& D$ intensity [24]. Among them, Ma and $\mathrm{Na}$ [25] introduced the absorption capacity and the proportion coefficient of innovation input distribution under the innovation collaboration mode of industry, university, and research institute and discussed its influence on the choice of government subsidy strategy. Dai and Cheng [26] believed that there is a bounded interval in the level of government subsidies. Through analysis, they pointed out that there is a saturation point in government subsidies, beyond which the further increase of government subsidies will not increase the company's R\&D investment. Wu et al. [5] thought that there is a critical point in government subsidies. Subsidy intensity below this point can induce enterprises' R\&D investment, while subsidy intensity above this point will squeeze out enterprises' R\&D investment. Zhang and Wang [27] put forward the incentive mechanism of benefit distribution based on different decision choices of members in the supply chain of new energy automobiles. The study found that centralized decision-making by members in the supply chain accelerated the steady development of the new energy automobile industry. Zhang and $\mathrm{Lu} \mathrm{[28]} \mathrm{and} \mathrm{Xu}$ and Sun [29] built a tripartite evolutionary game model of government, enterprises, and consumers based on game theory, aiming at the problems of uneven development of new energy automobile market, insufficient innovation of core technologies, and lack of government support, which provides reference for the sustainable and scientific development of new energy automobiles in China in the postsubsidy era. 
According to earlier discussion and analysis, existing researches have some shortcomings as follows: (1) there are few literatures that analyze government subsidies in innovation subjects, as well as the characteristics of decisionmaking behavior. In the R\&D of key technologies in the new energy automobile industry, each innovation subject is in a subordinate position, while the government is in a leader position. Moreover, the government can induce the innovation subject to carry out $\mathrm{R} \& \mathrm{D}$ activities to a certain extent but cannot make the innovation subject obey completely. However, the existing theories and methods cannot effectively describe and solve such incentive problems. (2) The existing research only qualitatively discusses the influence of government subsidies on enterprise $\mathrm{R} \& \mathrm{D}$ and optimizes government subsidy strategies. But it did not show the influence mechanism of government subsidies on the innovation behavior of innovative entities subjects. Therefore, it is necessary to study the influence mechanism of government subsidies on key technology R\&D subjects of the new energy automobile industry to improve R\&D efficiency [30]. So, on the basis of grey target negotiation model, considering government subsidy, this paper constructs a profit model and designs an incentive mechanism for key technologies $R \& D$ in new energy automobile industry. And the case verifies the effectiveness and stability of the proposed model.

\section{An Incentive Mechanism with Government Subsidy}

The R\&D of key technologies in the new energy automobile industry is a systematic project, which is a collaborative activity implemented by organizations or innovation alliances (such as industrial technology research institutes) composed of innovative subjects, such as universities, enterprises, research institutes, and financial institutions. However, the collaborative activity itself does not directly generate profits. In essence, its $\mathrm{R} \& \mathrm{D}$ process is a process of increasing the value of key technology $R \& D$ organization system of new energy automobile industry. In addition, the efforts and collaboration of innovation subjects affect the profits of R\&D organization system, which play a role in their expected profits distribution. In view of this, the effort of innovation subject is regarded as an important parameter for collaborative R\&D of key technologies in new energy automobile industry [30], and we construct an expected profit function of innovation subject and system of key technologies in new energy automobile industry. Then, from the perspective of government subsidy, we design a government subsidy incentive mechanism for R\&D of key technologies in the new energy automobile industry.

3.1. The Basic Profits Model. Suppose that there exists a government-led key technology innovation alliance of new energy automobile industry, which is composed of $n$ innovation subjects, such as enterprises, universities, research institutes, and financial institutions. The innovation subject set as $N=\{1, \ldots, i, \ldots, n\}$, where, $i(i=1,2, \ldots, n)$, represents the innovation subject. Among them, the government is in a dominant position because of its superior resources, such as capital, law, policy, and system, and can coordinate the R\&D behavior and interest relationship of $n$ innovation subjects. Under the coordination of the government, these innovative subjects actively cooperate in the R\&D of innovative technologies for new energy automobile industry, and the realization of the overall interests is the result of the efforts and collaborations of all innovative subjects. Among them, the efforts of each innovation subject not only affect their own expected interests but also affect R\&D organizations or innovation alliances. Generally speaking, the effort level of each innovation subject in the key technology innovation value chain system of the new energy automobile industry is mainly manifested in the resources, such as manpower, capital, equipment, and knowledge. Only by investing enough efforts can each innovation subject ensure successful R\&D of key technologies in the new energy automobile industry and then realize the value-added of key technology innovation value chain system in the new energy automobile industry. Therefore, the degree of effort and collaboration of each innovation subject is the key factor affecting the interests of technology innovation alliance of new energy automobile industry. According to the aforementioned analysis, we can construct the profit model for key technology $R \& D$ of new energy automobile industry.

In the collaborative R\&D of key technologies in the new energy automobile industry, the government coordinates each innovation subject through cost sharing, and the innovation subject will invest manpower, capital, equipment, and knowledge. The degree of effort and collaboration invested by the innovation subject will bring certain profits and pay a certain cost at the same time. This will affect the expected profits of the key technology innovation value chain system or organization of the new energy automobile industry and the expected profits of each innovation subject [31-33].

In the R\&D activities of key technologies in the new energy automobile industry, the profit function of the innovation subject is a function of the degree of effort $s_{i}$ and collaboration $c_{i}$, and that is in direct proportion. The higher the level of innovation subjects' efforts, the more the benefits they will get. However, the income growth rate of the innovation subject will become smaller with the increase of effort level, and after the innovation subject's effort level has increased to a certain extent due to the diminishing marginal returns in production exchange, no matter how it improves its effort level in the collaborative R\&D activities of innovative technologies, the income will not increase obviously. Assuming that $R_{i}\left(s_{i}, c_{i}\right)$ represents the expected return function of innovation subject $i$, and referring to Douglas production function, the expression of the expected return function of innovation subject $i$ in the key technology innovation value chain system of new energy automobile industry is as follows:

$$
R_{i}\left(s_{i}, c_{i}\right)=m_{i}+\alpha_{i}\left(c_{i} \sum_{i=1}^{n} c_{i}\right)\left(s_{i}\right)^{0.5}+\delta_{i} .
$$


Among them, $m_{i}\left(m_{i} \geq 0\right)$ is a fixed income, which means that the innovation subject $i$ can get the income with the lowest degree of effort and collaboration in the R\&D activities of key technologies in the new energy automobile industry; $\alpha_{i}\left(\alpha_{i}>0\right)$ is the effort benefit coefficient of innovation subject $i$. Moreover, in the actual situation, the income elasticity coefficient of the effort degree of the innovation subject is 0.5 . Owing to the uncertainty of innovative technology $\mathrm{R} \& \mathrm{D}, \delta_{i}$ is the random interference variable of the income of innovation subject $i$, $\delta_{i} \sim N\left(0, \sigma_{i}^{2}\right), E\left(\delta_{i}\right)=0, D\left(\delta_{i}\right)=\sigma_{i}^{2}$.

In the key technologies $\mathrm{R} \& \mathrm{D}$ activities in the new energy automobile industry, the cost function $W_{i}\left(s_{i}\right)$ of the innovation subject $i$ is a function about the degree of effort $s_{i}$. As the investment needs to pay a certain cost, in the R\&D of key technologies in the new energy automobile industry, the cost paid by the innovation subject is negatively correlated with the effort level, and with the increase of the effort level, the marginal cost increases. With reference to Douglas production function, the expression of cost function $W_{i}\left(s_{i}\right)$ of innovation subject $i$ on effort degree $s_{i}$ in key technology $R \& D$ value chain of new energy automobile industry is as follows:

$$
W_{i}\left(s_{i}\right)=\beta_{i}\left(s_{i}\right)^{2} .
$$

Among them, $\beta_{i}$ is the effort cost coefficient of innovation subject $i$. In addition, in the actual situation, the cost elasticity coefficient of innovation subject $i$ 's efforts is 2 .

In the key technology innovation value chain system of new energy automobile industry, the collaboration between innovation subject $i$ and other innovation subjects will affect its expected income, and there is no input cost. At the same time, the collaboration degree of innovation subject will have a negative effect on the expected return of subjecti. Let $c_{i}\left(0 \leq c_{i} \leq 1\right)$ and $f_{i}\left(c_{1}, \ldots, c_{i}, \ldots, c_{n}\right)$ express the collaboration degree between innovation subject $i$ and other innovation subjects and the negative effect of collaboration degree on the expected return of innovation subject $i$, respectively, and let $\pi_{i}\left(s_{i}, c_{i}\right)$ represent the expected profit function of innovation subject $i$. According to the expected return function, cost function, and return negative effect function of the innovation subject $i$, it will hold true as follows:

$$
\pi_{i}\left(s_{i}, c_{i}\right)=m_{i}+\alpha_{i}\left(c_{i} \sum_{i=1}^{n} c_{i}\right)\left(s_{i}\right)^{\frac{1}{2}}-\beta_{i}\left(s_{i}\right)^{2}-f_{i}\left(c_{1}, \ldots, c_{i}, \ldots, c_{n}\right) .
$$

Under normal circumstances, $\beta_{i}>\alpha_{i} \quad$ and
$m_{i}>f_{i}\left(c_{1}, \ldots, c_{i}, \ldots, c_{n}\right)$.
Let $S=\left\{s_{1}, \ldots, s_{i}, \ldots, s_{n}\right\}$ and $C=\left\{c_{1}, \ldots, c_{i}, \ldots, c_{n}\right\}$ be the effort set and collaboration set of the innovation subject, respectively, and the collaboration set has negative effect on the overall benefits of the key technology innovation value chain system of the new energy automobile industry, which is denoted as $f\left(c_{1}, \ldots, c_{i}, \ldots, c_{n}\right)$. The overall expected benefits, costs, and profits of the innovation value chain system are functions of the innovation subject's effort set $S=\left\{s_{1}, \ldots, s_{i}, \ldots, s_{n}\right\}$ and collaboration set $C=\left\{c_{1}, \ldots, c_{i}, \ldots, c_{n}\right\}$, which are recorded as $R(S, C)$, $W(S)$, and $\pi(S, C)$, respectively. Similar to the analysis and construction of the expected benefit function, expected cost function, and expected profit function of the innovation subject in the key technology innovation value chain system of the new energy automobile industry, their expressions are as follows:

$$
\begin{aligned}
& R(S, C)=m+\left(\sum_{i=1}^{n} c_{i}\right)\left[\lambda_{1}\left(s_{1}\right)^{\frac{1}{2}}+\cdots+\lambda_{i}\left(s_{i}\right)^{\frac{1}{2}}+\cdots+\lambda_{n}\left(s_{n}\right)^{\frac{1}{2}}\right]+\delta, \\
& W(S)=\theta_{1}\left(s_{1}\right)^{2}+\cdots+\theta_{i}\left(s_{i}\right)^{2}+\cdots+\theta_{n}\left(s_{n}\right)^{2}, \\
& \pi(S, C)=m+\left(\sum_{i=1}^{n} c_{i}\right) \sum_{i=1}^{n}\left[\lambda_{i}\left(s_{i}\right)^{\frac{1}{2}}\right]-\sum_{i=1}^{n}\left[\theta_{i}\left(s_{i}\right)^{2}\right]-f\left(c_{1}, \ldots, c_{i}, \ldots, c_{n}\right),
\end{aligned}
$$

where $m\left(m \geq \sum_{i=1}^{n} m_{i}\right)$ is the expected overall profits of the key technology innovation value chain system when the innovation subject invests in the lowest degree of effort and collaboration, and $m-\sum_{i=1}^{n} m_{i}$ is the fixed value-added income of the key technology innovation value chain system of the new energy automobile industry; $\lambda_{i}\left(\lambda_{i}>\alpha_{i}\right)$ is the profit coefficient of the innovation subject $i$ acting on the value chain system of technology innovation; $\theta_{i}\left(\theta_{i}>0\right)$ is the overall cost factor of the innovation subject $i$ acting on the technology innovation value chain system; and $\theta_{i}<\beta_{i}$. In 
general, $\lambda_{i}>\theta_{i}$ and $m>f\left(c_{1}, \ldots, c_{i}, \ldots, c_{n}\right) . \delta$ is a random disturbance variable for the expected overall profits of the value chain system of the key technology innovation in the new energy automobile industry, $\delta \sim N\left(0, \sigma^{2}\right), E(\delta)=0$, and $D(\delta)=\sigma^{2}$.

\subsection{Analysis of Equilibrium Strategies without Government Subsidies}

3.2.1. Noncooperative Equilibrium Strategies. In the value chain system of key technology innovation in the new energy automobile industry, when each innovation subject chooses noncollaboration, each subject adopts the equilibrium strategy of maximizing its own interests. That is, it considers the level of effort to maximize the expected profits $\pi_{i}\left(s_{i}, c_{i}\right)$. Let $S^{*}=\left(s_{1}^{*}, \ldots, s_{i}^{*}, \ldots, s_{n}^{*}\right)$ denote the optimal level of effort of the innovation subject when noncooperative, and from Nash equilibrium. Theorem 1 is obtained.

Theorem 1. In the value chain system of key technology innovation in the new energy automobile industry, when the innovation subject chooses a noncooperative strategy, its optimal level of effort satisfies the following equation:

$$
\left(s_{1}^{*}, \ldots, s_{i}^{*}, \ldots, s_{n}^{*}\right)=\left(\left(\frac{\alpha_{1}}{4 \beta_{1}} c_{1} \sum_{i=1}^{n} c_{i}\right)^{\frac{2}{3}}, \ldots,\left(\frac{\alpha_{i}}{4 \beta_{i}} c_{i} \sum_{i=1}^{n} c_{i}\right)^{\frac{2}{3}}, \ldots,\left(\frac{\alpha_{n}}{4 \beta_{n}} c_{n} \sum_{i=1}^{n} c_{i}\right)^{\frac{2}{3}}\right.
$$

Proof: By solving the partial derivative of $\pi_{i s_{i}}\left(s_{i}, c_{i}\right)$ overs $s_{i}$, let $\pi_{s_{i}}^{\prime}\left(s_{i}, c_{i}\right)=0$, we can obtain the following:

$$
\begin{aligned}
s_{i} & =\left(\frac{\alpha_{i}}{4 \beta_{i}} c_{i} \sum_{i=1}^{n} c_{i}\right)^{\frac{2}{3}}, \\
\pi_{i_{s_{i}} s_{i}}^{\prime \prime}\left(s_{i}, c_{i}\right) & =-\frac{1}{4} \alpha_{i}\left(c_{i} \sum_{i=1}^{n} c_{i}\right)\left(s_{i}\right)^{-\frac{3}{2}}-2 \beta_{i} .
\end{aligned}
$$

As $0<\eta_{i}<1$ and $\mu_{i}>1$, when $s_{i}=\left(\alpha_{i} / 4 \beta_{i} c_{i} \sum_{i=1}^{n} c_{i}\right)^{2 / 3}$, if there exist the existence of a unique extreme for $\pi_{i s_{i}}\left(s_{i}, c_{i}\right)$, then we will have $s_{i}^{*}=\left(\alpha_{i} / 4 \beta_{i} c_{i} \sum_{i=1}^{n} c_{i}\right)^{2 / 3}$.

Based on Theorem 1, Conclusion 1 can be obtained.
Conclusion 1: In the value chain system of key technology innovation in the new energy automobile industry, if each innovation subject chooses noncollaboration, the optimal effort level $s_{i}^{*}$ of innovation subject $i$ depends on the effort benefit coefficient $\alpha_{i}$, the effort cost coefficient $\beta_{i}$, and the degree of collaboration $c_{i}$. The larger the efforts benefit coefficient and the degree of collaboration, the smaller the effort cost coefficient and the larger the optimal effort level, and vice versa.

Therefore, the optimal expected profit function of innovation subject $i$ and the expected overall profit function of the value chain system of key technology innovation in the new energy automobile industry are as follows:

$$
\begin{aligned}
& \pi_{i}^{*}\left(s_{i}^{*}, c_{i}\right)=m_{i}+\alpha_{i}\left(c_{i} \sum_{i=1}^{n} c_{i}\right)\left(\frac{\alpha_{i}}{4 \beta_{i}} c_{i} \sum_{i=1}^{n} c_{i}\right)^{\frac{1}{3}}-\beta_{i}\left(\frac{\alpha_{i}}{4 \beta_{i}} c_{i} \sum_{i=1}^{n} c_{i}\right)^{\frac{4}{3}}-f_{i}\left(c_{1}, \cdots, c_{i}, \cdots, c_{n}\right), \\
& \pi^{*}\left(S^{*}, C\right)=m+\left(\sum_{i=1}^{n} c_{i}\right) \sum_{i=1}^{n}\left[\lambda_{i}\left(\frac{\alpha_{i}}{4 \beta_{i}} c_{i} \sum_{i=1}^{n} c_{i}\right)^{\frac{1}{3}}\right]-\sum_{i=1}^{n}\left[\theta_{i}\left(\frac{\alpha_{i}}{4 \beta_{i}} c_{i} \sum_{i=1}^{n} c_{i}\right)^{\frac{4}{3}}\right]-f\left(c_{1}, \cdots, c_{i}, \cdots, c_{n}\right) .
\end{aligned}
$$

3.2.2. Cooperative Equilibrium Strategies. When the innovation subjects in the key technology innovation value chain system of the new energy automobile industry choose to cooperate, their first consideration is the level of effort to maximize the overall expected profits, let $S^{* *}=\left(s_{1}^{* *}, \ldots, s_{i}^{* *}, \ldots s_{n}^{* *}\right)$ denote the optimal level of effort of the innovation subjects when cooperating, according to the overall expected profits of the key technology innovation value chain system of the new energy automobile industry can be obtained from Theorem 2 .

Theorem 2. In the value chain system of key technology innovation in the new energy automobile industry, when the innovation subject chooses a cooperative R\&D strategy, its optimal level of effort satisfies as follows: 


$$
\left(s_{1}^{* *}, \cdots, s_{i}^{* *}, \cdots s_{n}^{* *}\right)=\left(\left(\frac{\lambda_{1}}{4 \theta_{1}} \sum_{i=1}^{n} c_{i}\right)^{\frac{2}{3}}, \ldots,\left(\frac{\lambda_{i}}{4 \theta_{i}} \sum_{i=1}^{n} c_{i}\right)^{\frac{2}{3}}, \ldots,\left(\frac{\lambda_{n}}{4 \theta_{n}} \sum_{i=1}^{n} c_{i}\right)^{\frac{2}{3}}\right)
$$

Proof: According to $\pi(S, C)$, then we have

$$
\partial \pi \frac{(S, C)}{\partial s_{i}}=\frac{1}{2} \lambda_{i}\left(\sum_{i=1}^{n} c_{i}\right)\left(s_{i}\right)^{-\frac{1}{2}}-2 \theta_{i} s_{i} .
$$

Letting $\partial \pi(S, C) / \partial s_{i}=0$, it is possible to obtain

$$
s_{i}^{* *}=\left(\frac{\lambda_{i}}{4 \theta_{i}} \sum_{i=1}^{n} c_{i}\right)^{2 / 3} .
$$

It is the stable point of the optimal level of effort of the innovation subject $i$, while the second-order partial derivative of the stable point is

$$
\pi_{s_{i} s_{i}}^{\prime \prime}\left(s_{1}, s_{2}, \ldots, s_{n}\right)=-\frac{1}{4} \lambda_{i}\left(\sum_{i=1}^{n} c_{i}\right)\left(s_{i}\right)^{-\frac{3}{2}}-2 \theta_{i} .
$$

Since $0<\eta_{i}<1, \mu_{i}>1, \lambda_{i}>0$, and $\theta_{i}>0$, there is $\pi_{s_{i} s_{i}}^{\prime \prime}\left(s_{1}^{* *}, s_{2}^{* *}, \ldots, s_{n}^{* *}\right)<0, \quad$ and since $Z_{\pi s_{i} s_{j}}^{\prime \prime}\left(s_{1}^{* *}, s_{2}^{* *}, \ldots, s_{n}^{* *}\right)=0$ and $i \neq j$, there are stable points of second-order partial derivatives of the sequential principal subformat matrix taking negative values of

$$
-B=\left[\begin{array}{c}
\frac{1}{4}\left(\sum_{i=1}^{n} c_{i}\right)\left(s_{1}\right)^{-\frac{3}{2}}+2 \theta_{1}, 0, \ldots, 0 \\
0, \frac{1}{4} \alpha_{2}\left(\sum_{i=1}^{n} c_{i}\right)\left(s_{2}\right)^{-\frac{3}{2}}+2 \theta_{2}, \ldots, 0 \\
\vdots \quad \vdots \\
0, \ldots 0, \frac{1}{4} \alpha_{n}\left(\sum_{i=1}^{n} c_{i}\right)\left(s_{n}\right)^{-\frac{3}{2}}+2 \theta_{n}
\end{array}\right] .
$$

Since the main subformula of each order of the matrix $-B$ is greater than 0 , the expected profit function $\pi(S, C)$ of the key technology innovation value chain system of the new energy automobile industry as a whole achieves the maximum value at the stable point $\left(\left(\lambda_{1} / 4 \theta_{1} \sum_{i=1}^{n} c_{i}\right)^{2 / 3}\right.$ $\left., \ldots,\left(\lambda_{i} / 4 \theta_{i} \sum_{i=1}^{n} c_{i}\right)^{2 / 3}, \ldots,\left(\lambda_{n} / 4 \theta_{n} \sum_{i=1}^{n} c_{i}\right)^{2 / 3}\right)$.

Based on Theorem 2, there is Conclusion 2.

Conclusion 2: In the value chain system of key technology innovation in the new energy automobile industry, if each innovation subject chooses to cooperate, the optimal degree of effort $s_{i}^{* *}$ of innovation subject $i$ depends on the value chain benefit coefficient $\lambda_{i}$, the value chain cost coefficient $\theta_{i}$, and the degree of collaboration $c_{i}$, and the greater the value chain benefit coefficient and the degree of collaboration, the smaller the value chain cost coefficient and the greater the optimal degree of effort, and vice versa.

Therefore, the optimal expected profit function of innovation subject $i$ and the overall profit function of the value chain system of key technology innovation in the new energy automobile industry are as follows:

$$
\begin{aligned}
& \pi_{i}^{* *}\left(s_{i}^{* *}, c_{i}\right)=m_{i}+\alpha_{i}\left(c_{i} \sum_{i=1}^{n} c_{i}\right)\left(\frac{\lambda_{i}}{4 \theta_{i}} \sum_{i=1}^{n} c_{i}\right)^{\frac{1}{3}}-f_{i}\left(c_{1}, \ldots, c_{i}, \ldots, c_{n}\right) \\
& \pi^{* *}\left(S^{* *}, C\right)=m+\left(\sum_{i=1}^{n} c_{i}\right) \sum_{i=1}^{n}\left[\lambda_{i}\left(\frac{\lambda_{i}}{4 \theta_{i}} \sum_{i=1}^{n} c_{i}\right)^{\frac{1}{3}}\right]-\sum_{i=1}^{n}\left[\theta_{i}\left(\frac{\lambda_{i}}{4 \theta_{i}} \sum_{i=1}^{n} c_{i}\right)^{\frac{4}{3}}\right]-f\left(c_{1}, \ldots, c_{i}, \ldots, c_{n}\right) .
\end{aligned}
$$


According to the above analysis, in the absence of government subsidies, key technology innovation subjects in the new energy automobile industry can choose between collaborative or noncooperative $\mathrm{R} \& \mathrm{D}$. When innovation subjects choose noncooperative R\&D, they maximize their own expected profits, and when innovation subjects choose collaborative $\mathrm{R} \& \mathrm{D}$, they maximize the expected profits of the overall technology innovation value chain. When an innovation subject chooses noncooperative $\mathrm{R} \& \mathrm{D}$, it maximizes its own expected profits, and when an innovation subject chooses cooperative R\&D, it maximizes the expected profits of the technology innovation value chain system as a whole. However, innovation subjects are rational and have the pursuit of profits maximization as their decision objective, and depending on $\pi_{i}^{*}\left(s_{i}^{*}, c_{i}\right) \geq \pi_{i}^{* *}\left(s_{i}^{* *}, c_{i}\right)$, they may invest a level of effort $s_{i}^{*}$ with a view to ensuring that their desired profits is not lost. At the same time, $\pi^{*}\left(S^{*}, C\right) \leq \pi^{* *}\left(S^{* *}, C\right)$; therefore, the degree of effort $s_{i}^{*}$ is difficult to achieve the optimal profits expected by the technology innovation value chain system as a whole and to ensure the success of key technology R\&D in the new energy automobile industry, so government subsidies are needed to motivate each innovation subject and make its degree of effort infinitely close to or even equal to $s_{i}^{* *}$.

\subsection{Incentive Model Based on Grey Target Negotiation for Key Technologies R\&D}

3.3.1. Grey Bull's-Eye Group Negotiation. Due to the differences in systems, environments, interests, and goals, we form a multilevel and complex network relationship between key technology innovation subjects in the new energy automobile industry. The essence of this network relationship is the synergistic relationship of interests in the key technology innovation network of the new energy automobile industry (unless otherwise stated, the interests mentioned in this paper refer to such broad interests). However, in government-led industrial technology innovation alliances (such as the Industrial Technology Research Institute), each innovation subject tends to choose its own ideal level of effort based on maximizing interests, while innovation alliances tend to expect each innovation subject to follow its required alliance desired level of effort based on maximizing overall interests. Since investing in the level of effort means increasing the cost, the overall benefit of each innovation subject is lower than the previous benefit and they are not willing to invest in the level of effort as required by the technology innovation value chain system. Therefore, in order to mobilize the enthusiasm and motivation of innovation subjects, the government relies on its own policy, institutional, legal, and financial resources to subsidize some of the financial resources to encourage innovation subjects to make their best efforts and collaboration, which may be based on the requirements of the innovation alliance value chain system.

Let the innovation alliance have a coordinator (in this paper, the government) and $n$ general stakeholders (in this paper, the innovation subjects). Let $P_{0 i}=\left(p_{0 i 1}, \ldots, p_{0 i k}, \ldots, p_{0 i m}\right)$ be the multidimensional bull's-eye of the coordinator after consultation with the innovation subject group and $P_{i}=\left(p_{i 1}, \ldots, p_{i k}, \ldots, p_{i m}\right)$ be the multidimensional grey bull's-eye of the innovation subject $i$, which is the optimal solution or countermeasure according to its own cognition and ability, and accordingly, the bull's-eye distance of the stakeholder $i$ before and after consultation is the $m$-dimensional bull's-eye distance. Considering the different importance of each target to the innovation group, let $\tau_{k}$ be the weight of target $k$, which indicates the degree of importance, then the bull's-eye distance before and after the innovation subject group consultation is

$$
f_{i}(p)=\left(\sum_{k=1}^{m} \tau_{k}\left|p_{i k}-p_{0 k}\right|^{2}\right)^{\frac{1}{2}}
$$

where $\tau_{k}$ denotes the degree of importance of the target $k$.

The interest claims of innovation actors are often based on their own perceptions, which are expressed in real life as an opinion or viewpoint. Accordingly, the interest claims of the innovation alliance value chain system are generated by the perceptions of the coordinator and the innovation subject, but this claim or perception is based on the coordination of the coordinator not only considering his own interests, but more importantly, the interests of the system. Let $w_{i}$ denote the unit cost paid to the innovator by the coordinator for persuading the innovator to comply with the cognitive bull's-eye shift to the group bull's-eye (the level of effort solution set by the coordinator from the system optimum, also known as the system ideal level of effort solution), and $₫(\bowtie \geq 1)$ denotes the coordinator's subsidy coefficient, then $w_{i}\left[f_{i}(p)\right]^{\Phi}$ denotes the cost to be compensated to the innovator by the coordinator for getting the innovator to comply with the group grey bull's-eye. The smaller the value of $w_{i}\left[f_{i}(p)\right]^{\varpi}$, the closer the stakeholder $i$ 's own perceived grey bull's-eye is to the group grey bull's-eye, and the lower the cost of government subsidies to the innovator $i$. If the costs $w_{i}\left[f_{i}(p)\right]^{\varpi}$ paid by the coordinator to coordinate all stakeholders are summed, a weighted geometric mean $\sum_{i=1}^{n} w_{i}\left[f_{i}(p)\right]^{\Phi}$ is obtained, which can represent the total coordination cost of the coordinator to make the innovation subject obey the group grey bull's-eye. For the coordinator, the smaller the $\sum_{i=1}^{n} w_{i}\left[f_{i}(p)\right]^{\Phi}$, the smaller the deviation of the innovation subject's own perceived grey bull's-eye from the group grey bull's-eye, and the lower the coordination cost paid by the coordinator to all innovation subjects. Let $B$ be the total coordination cost of coordinating 
innovation subjects by the coordinator, then we can construct an incentive model based on grey target negotiation.

$\min B$,

$$
\text { s.t. }\left\{\begin{array}{l}
\sum_{i=1}^{n} w_{i}\left[\left(\sum_{k=1}^{m} \tau_{k}\left|p_{i k}-p_{0 i k}\right|^{2}\right)^{\frac{1}{2}}\right]^{\Phi}=B \\
\sum_{k=1}^{m} \tau_{k}=1 \\
i=1,2, \ldots, n \\
k=1,2, \ldots, m
\end{array}\right.
$$

This single-objective optimization model must have a unique optimal solution, which means that the general population consensus bull's-eye $P_{0 i}=\left(p_{0 i 1}, \ldots, p_{0 i k}, \ldots, p_{0 i m}\right)$.

To achieve a unique consensus among all groups with different objectives, the following single-objective consensus grey target negotiation model is available.

$\min B$,

$$
\text { s.t. }\left\{\begin{array}{l}
\sum_{i=1}^{n} w_{i}\left[\left(\sum_{k=1}^{m} \tau_{k}\left|p_{i k}-p_{0 i k}\right|^{r}\right)^{\frac{1}{r}}\right]^{\varpi}=B, \\
p_{01 k}=\cdots p_{0 i k}=\cdots=p_{0 n k}, \\
p_{0 i k}=p_{0 k}, \\
\sum_{k=1}^{m} \tau_{k}=1, \\
i=1,2, \ldots, n, \\
k=1,2, \ldots, m .
\end{array}\right.
$$

It is easy to prove that this single-objective optimization model must have a unique optimal solution, which means that the general population consensus bull's-eye $P_{0}=\left(p_{01}, \ldots, p_{0 k}, \ldots, p_{0 m}\right)$.

3.3.2. Utility Function with Risk Attitude. In the collaborative innovation activities, due to the natural barriers of the secondary development and technology diffusion of key technologies in the new energy automobile industry as well as the uncertainties of technology and market, the expected interests of innovation subjects may change, making them unwilling to continue to invest in $\mathrm{R} \& \mathrm{D}[34,35]$, so that the innovation subjects present the decision-making behavior of risk attitude, and the utility level of the innovation subjects will follow the parabolic pattern of change rule as the expected profits increase. For the government, to maximize social benefits, it vigorously supports technology R\&D activities and constantly introduces relevant policies (such as the construction of science and technology service platform). At this time, the government's utility is increasing with the increase of expected profits of the technology innovation value chain system, but the utility obeys the rightleaning S-shaped change rule. Considering the different status, cognition, and ability of the innovation subject and the government, the decision-making behavior of the government and the innovation subject in the key technology innovation value chain system of the new energy automobile industry presents different preference structure and influences the final consensus degree of the group to some extent.

In the key technology innovation value chain system of new energy automobile industry, although the process of $\mathrm{R} \& \mathrm{D}$ is accompanied by complex uncertainties and risks, with the continuous deepening of $R \& D$ and the input of innovation subjects' efforts and collaboration, the benefits gradually become prominent. According to the aforementioned analysis and the utility function of Gong et al.'s study [36], the utility function of the innovation subject and the government's expected profits are interval parabolic and right-biased S-shaped expected profits utility functions, respectively, as shown in Figures 1 and 2.

As shown in Figure 1, in the expected profits range $\left[a_{i 1}, a_{i 2}\right]$, the innovation subject seeks to obtain the profits matching its ability by increasing its efforts, and the marginal utility of its profits increases with the increase of the expected profits. When the expected profits reach the maximum in the case of noncollaboration, the utility of the innovation subject reaches the maximum. Within the range of expected profits $\left[a_{i 2}, a_{i 3}\right]$, due to the coordination of government subsidies, the adjustment efforts of innovative subject receives more government subsidies. As the increasing marginal cost, innovation subject needs to take a higher development costs, but its expected profits continue to increase, so the innovation subject ability within the scope of its utility is stable at the highest level. In the expected profits range $\left[a_{i 3}, a_{i 4}\right]$, the utility level of the innovation subject decreases with the increase of the expected profits, and the marginal utility increases with the increase of the expected profits. That is because in the right interval, the pursuit of more expected profits requires more efforts and correspondingly more R\&D risks and costs, which puts forward higher requirements on the learning and reinnovation ability of the innovation subjects. As a result, the uncertainty of the future earnings of the innovation subjects increases and the satisfaction decreases. As the expected profits increases, satisfaction decreases, resulting in diminishing utility. According to the aforementioned analysis, the utility function of the technology innovation subject is expressed as follows: 


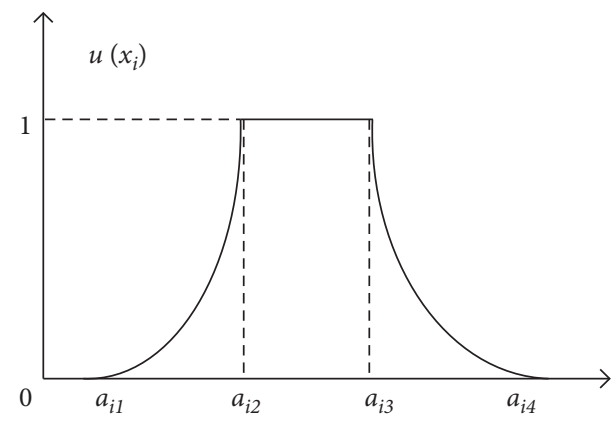

Figure 1: Interval parabola type expected profits utility function.

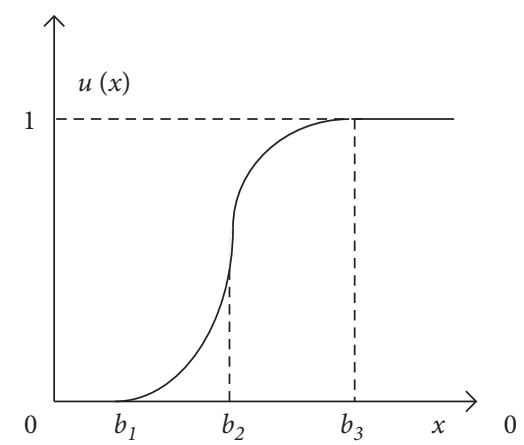

FIGURE 2: Right-skewed S-shaped overall expected profits utility function.

$$
U\left(x_{i}\right)=\left\{\begin{array}{l}
0, x_{i} \leq a_{i 1}, \\
\left(\frac{x_{i}-a_{i 1}}{a_{i 2}-a_{i 1}}\right)^{2}, a_{i 1} \leq x_{i} \leq a_{i 2}, \\
1, a_{i 2} \leq x_{i} \leq a_{i 3}, \\
\left(\frac{a_{i 4}-x_{i}}{a_{i 4}-a_{i 3}}\right)^{2}, a_{i 3} \leq x_{i} \leq a_{i 4}, \\
0, x_{i} \geq a_{i 4},
\end{array}\right.
$$

As for Figure 2, in the overall expected profits range $\left[b_{1}, b_{2}\right]$, the government coordinates the innovation subject's self-cognition effort through subsidies to the optimal effort of the system. The marginal utility of profits increases with the increase of the overall expected profits of the system, and the government's utility function at this point is risk preference. In the overall expected profits range $\left[b_{2}, b_{3}\right]$, to maximize the total expected profits of the technology innovation value chain system, the effort of the innovation subject coordinated by the government through subsidies is close to or equal to the optimal effort of the system, at this point, the government needs to bear the higher subsidy cost, and the marginal utility of profits will decrease with the increase of the system's overall expected profits. Meanwhile, the government always hopes that the bigger the overall expected profits of the value chain system of key technology innovation in the new energy automobile industry is better. At this time, the government's utility is stable at the highest level in the range $\left[b_{3},+\infty\right)$. According to the aforementioned analysis, the utility function of the government is expressed as follows:

$$
U(x)=\left\{\begin{array}{l}
0, x \leq b_{1} \\
\frac{1}{2}+\frac{1}{2} \sin \frac{\pi}{b_{3}-b_{1}}\left(x-b_{i 2}\right), b_{1} \leq x \leq b_{3} \\
1, x \geq b_{3}
\end{array}\right.
$$

3.3.3. Grey Target Negotiation Incentive Model considering the Preferences of Innovation Subjects. Since the incentive goal of this paper is the degree of effort, that is $k=1$. At this point, the multitarget negotiation bull's-eye in the grey target negotiation model is simplified to the single target negotiation bull's-eye. So, $f_{i}(s)=\left|s_{i}-s_{i}^{* * *}\right|$, $w_{i}\left[f_{i}(s)\right]^{\Phi}=w_{i}\left|s_{i}-s_{i}^{* * *}\right|^{\Phi}, \quad$ and $\quad \sum_{i=1}^{n} w_{i}\left[f_{i}(s)\right]^{\Phi}$ $=\sum_{i=1}^{n} w_{i}\left|s_{i}-s_{i}^{* * *}\right|^{\Phi}$. Based on the grey target negotiation model, the government encourages the innovators to change their self-cognitive effortss $s_{i}$ to the group target $s_{i}^{* * *}$ through R\&D subsidies. Then $w_{i}\left|s_{i}-s_{i}^{* * *}\right|^{\oplus}$ represents the cost that the government should compensate the innovators $i$ for making the innovators obey the group target. The smaller the value of $w_{i}\left|s_{i}-s_{i}^{* * *}\right|^{\varpi}$, the closer the distance between the innovators' self-cognitive target and the group consensus target. If the cost $w_{i}\left|s_{i}-s_{i}^{* * *}\right|^{\varpi}$ paid by the government to coordinate all innovation subjects is added together, a weighted geometric mean value $\sum_{i=1}^{n} w_{i}\left|s_{i}-s_{i}^{* * *}\right|^{\varpi}$ can be obtained, which represents the total coordination cost of the government to make the innovation subject obey the group consensus target. The $w_{i}$ is the unit subsidy cost of the government to persuade the innovation subject to change its effort level to the optimal effort level of the system, and $s_{i}^{* * *}$ is the equilibrium stable solution. From the perspective of the innovation subject, $w_{i}\left|s_{i}-s_{i}^{* * *}\right|^{\oplus}$ also represents the additional expected profits, so the expected profit function expression of the innovation subject is

$$
\pi_{i}^{* * *}\left(s_{i}^{* * *}, c_{i}\right)_{G}=m_{i}+\alpha_{i}\left(c_{i} \sum_{i=1}^{n} c_{i}\right)\left(s_{i}^{* * *}\right)^{\frac{1}{2}}-\beta_{i}\left(s_{i}^{* * *}\right)^{2}-f_{i}\left(c_{1}, \ldots, c_{i}, \ldots, c_{n}\right)+w_{i}\left|s_{i}-s_{i}^{* * *}\right|^{\varpi} .
$$


Let $\xi$ represent the utility of value chain of key technology innovation in the new energy automobile industry (including the utility of innovation subjects and the government), and it equals to the lowest utility of the participants in the technology innovation value chain system. If the lowest utility of the participants reaches the optimal, the optimal utility of the entire technology innovation value chain system will be realized. Under the condition that the expected profits of each innovation subject is not lost, the utility of the technology innovation value chain system is maximized, and the overall expected profits of the technology innovation value chain system is optimized. The government subsidy incentive model based on grey target negotiation is constructed as follows:

$$
\begin{aligned}
& \max \xi \\
& \max \pi^{* * *}\left(S^{* * *}, C\right), \\
& \operatorname{s.t.}\left\{\begin{array}{l}
\sum_{i=1}^{n} w_{i}\left|s_{i}-s_{i}^{* * *}\right|^{\varpi}=B, \\
\xi \leq\left[\frac{\pi_{i}^{* * *}\left(s_{i}^{* * *}, c_{i}\right)_{G}-a_{i 1}}{a_{i 2}-a_{i 1}}\right]^{2}, \\
\xi \leq\left[\frac{a_{i 4}-\pi_{i}^{* * *}\left(s_{i}^{* * *}, c_{i}\right)_{G}}{a_{i 4}-a_{i 3}}\right]^{2}, \\
\pi_{i}^{* * *}\left(s_{i}^{* * *}, c_{i}\right)_{G} \geq \pi_{i}^{*}\left(s_{i}^{*}, c_{i}\right), \\
\pi_{i}^{* * *}\left(s_{i}^{* * *}, c_{i}\right)_{G} \geq \pi_{i}\left(s_{i}, c_{i}\right), \\
\pi_{i}^{* * *}\left(s_{i}^{* * *}, c_{i}\right)_{G} \geq \pi_{i}^{* *}\left(s_{i}^{* *}, c_{i}\right), \\
0 \leq \xi) \geq \pi^{*}\left(S^{*}, C\right), \\
\pi_{3}-b_{1}\left[\pi^{* * *}\left(S^{* * *}, C\right)-b_{2}\right],
\end{array}\right.
\end{aligned}
$$

Among them, $\xi \leq\left[\pi_{i}^{* * *}\left(s_{i}^{* * *}, c_{i}\right)_{G}-a_{i 1} / a_{i 2}-a_{i 1}\right]^{2}$ and $\xi \leq\left[a_{i 4}-\pi_{i}^{* * *}\left(s_{i}^{* * *}, c_{i}\right)_{G} / a_{i 4}-a_{i 3}\right]^{2}$ are the expected profits utility constraint of innovation subject $i$, and $\xi \leq 1 / 2+1 / 2 \sin \pi / b_{3}-b_{1}\left[\pi^{* * *}\left(S^{* * *}, C\right)-b_{2}\right]$ is the government's utility constraint on the overall expected profits of the system; $\pi_{i}^{* * *}\left(s_{i}^{* * *}, c_{i}\right)_{G} \geq \pi_{i}\left(s_{i}, c_{i}\right), \pi_{i}^{* * *}\left(s_{i}^{* * *}, c_{i}\right)_{G}$ $\geq \pi_{i}^{*}\left(s_{i}^{*}, c_{i}\right)$, and $\pi_{i}^{* * *}\left(s_{i}^{* * *}, c_{i}\right)_{G} \geq \pi_{i}^{* *}\left(s_{i}^{* *}, c_{i}\right)$ indicate that the expected profits after subsidy is greater than the expected profits before subsidy, so that the innovation subjects will accept the government's efforts to coordinate consensus. In addition, although the expected overall profits of the system after incentive cannot be guaranteed to be equal to $\pi^{* *}\left(S^{* *}, C\right)$, it must be greater than $\pi^{* *}\left(S^{* *}, C\right)$ and $\pi(S, C)$, so government subsidies make sense. Based on this optimization model, the equilibrium stable solution $S^{* * *}=$ $\left\{s_{1}^{* * *}, \ldots, s_{i}^{* * *}, \ldots, s_{n}^{* * *}\right\}$ can be obtained.

\section{Numerical Cases}

With the serious energy crisis and environmental pollution, Chinese government pays more and more attention to the industrialization process of new energy vehicles. With the government's vigorous advocacy and policy support, all regions of our country are active and invest in product development, demonstration, and promotion of new energy vehicles. The "New Energy Automobile Industry Development Plan (2021-2035)" on November 2, 2020, proposed that the development of new energy vehicles is the only way for my country to move from a major automobile country to a powerful automobile country and is a strategic measure to tackle climate change and promote green development. Therefore, it is of great significance to study the R\&D incentive mechanism of key technologies in the new energy automobile industry. We will take Baoneng New Energy Automobile Group as the research object to study the effectiveness of the incentive mechanism proposed in this paper.

Baoneng New Energy Automobile Group mainly launches extended-range electric vehicle iREV and pure electric Bev models and achieves full coverage of market demand through diversification of product layout. In addition, the company is currently looking forward to research and development of hydrogen energy vehicles to further enrich the company's product structure. To build a national automobile brand and master the core technology with independent intellectual property rights, Baoneng New Energy Automobile Group adheres to the road of independent research and development, has an international technology research and development team that is completely independent, and has an international leading level.

For vehicle $\mathrm{R} \& \mathrm{D}$, Baoneng Automobile Group implements the $1+\mathrm{N}$ model, a global R\&D headquarters (Shenzhen Research Institute), plus Guangzhou Research Institute, Xi'an Research Institute, Shenzhen Research Institute, and Shanghai (Qoros) Research Institute; for component R\&D, Baoneng Automobile Group has established Hongpeng New Energy and Zhenyu New Energy to conduct research and development of power batteries, motors, and electronic controls, respectively; for research institute construction, Baoneng Automobile Group established its Shenzhen Global Research Headquarters. The Intelligent Network Institute has established a battery and new energy research and development center in Japan and plans to establish a German engineering center, an American forward-looking technology center, and an Italian modeling center. A series of intelligent interconnection and new energy enterprises incubated by Baoneng Science and Technology Park together constitute Baoneng's complete R\&D system for parts and components. 
Regarding the aforementioned R\&D incentive mechanism of Baoneng New Energy Automobile Group's entire industry chain, a representative institution was selected for modeling in key links, such as vehicle R\&D, component $\mathrm{R} \& \mathrm{D}$, and research institute construction. The four innovation entities of the government, Shenzhen Research Institute, Hongpeng New Energy, and Intelligent Networking Institute are respectively recorded as $N=\{1,2,3,4\}$. Due to the confidentiality of the R\&D system, it is difficult for us to obtain relevant data. Therefore, we obtain relevant parameters through consulting experts and historical experience. The relevant parameter values are shown in Table 1.

According to relevant parameters, the equilibrium strategy of innovative technology R\&D of new energy automobile under the condition of nongovernment subsidies is calculated, as shown in Tables 2 and 3. It can be seen that the expected profits of the innovation subject in the noncooperative case is better than that in the cooperative case. The technology innovation value chain system expects the overall profits to be worse than the cooperative case.

As the innovation subject is rational and takes the pursuit of maximization as the decision-making goal, and then, the self-cognitive effort of the innovation subject is $s_{i}=s_{i}^{*}$. On the basis of the aforementioned calculation results, the incentive model of this case is constructed according to equation (17). According to the previous R\&D experience of innovative technologies of new energy automobile and relevant policies, there is $w_{1}=10, w_{2}=10, w_{3}=13, w_{4}=8, B=60$, and $\Phi=1$.

$\max \xi$

$\max \pi^{* * *}\left(S^{* * *}, C\right)$

$$
\left\{\begin{array}{l}
w_{1}\left|0.0976-s_{1}^{* * *}\right|+w_{2}\left|0.1234-s_{2}^{* * *}\right|+w_{3}\left|0.1275-s_{3}^{* * *}\right|+w_{4}\left|0.1517-s_{4}^{* * *}\right|=60, \\
\xi \leq\left[\frac{\pi_{1}^{* * *}\left(s_{1}^{* * *}, c_{1}\right)_{G}-0}{11.4784-0}\right]^{2}, \xi \leq\left[\frac{26-\pi_{1}^{* * *}\left(s_{1}^{* * *}, c_{1}\right)_{G}}{26-20}\right]^{2}, \\
\xi \leq\left[\frac{\pi_{2}^{* * *}\left(s_{2}^{* * *}, c_{2}\right)_{G}-0}{13.5110-0}\right]^{2}, \xi \leq\left[\frac{26-\pi_{2}^{* * *}\left(s_{2}^{* * *}, c_{2}\right)_{G}}{26-18}\right]^{2}, \\
\xi \leq\left[\frac{\pi_{3}^{* * *}\left(s_{3}^{* * *}, c_{3}\right)_{G}-0}{4.3937-0}\right]^{2}, \xi \leq\left[\frac{26-\pi_{3}^{* * *}\left(s_{3}^{* * *}, c_{3}\right)_{G}}{26-19}\right]^{2}, \\
\xi \leq\left[\frac{\pi_{4}^{* * *}\left(s_{4}^{* * *}, c_{4}\right)_{G}-0}{16.8095-0}\right]^{2}, \xi \leq\left[\frac{26-\pi_{4}^{* * *}\left(s_{4}^{* * *}, c_{4}\right)_{G}}{26-22}\right]^{2}, \\
\pi^{* * *}\left(s^{* * *}, C\right) \geq 73.4316, \\
\pi_{3}^{* * *}\left(s_{3}^{* * *}, c_{3}\right)_{G} \geq 4.3937, \pi_{4}^{* * *}\left(s_{4}^{* * *}, c_{4}\right)_{G} \geq 16.8095, \\
\pi_{1}^{* * *}\left(s_{1}^{* * *}, c_{1}\right)_{G} \geq 11.4784, \pi_{2}^{* * *}\left(s_{2}^{* * *}, c_{2}\right)_{G} \geq 13.5110, \\
\frac{1}{2}+\frac{1}{\sin } \frac{1.6471-0.0000}{26}\left[\pi^{* * *}\left(S^{* * *}, C\right)-80\right],
\end{array}\right.
$$

We can exploit the ideal point method to convert multiobjective programming into single-objective programming. Using MATLAB, the results can be obtained and shown in Table 4.
According to the calculation results in Table 4, the expected profits of the innovation subjects exceed the noncooperative level, and the vast majority exceeds the collaboration level, and the degree of effort is significantly 
TABLE 1: Relevant parameter table.

\begin{tabular}{lccccccc}
\hline Innovation subject & $\alpha_{i}$ & $\beta_{i}$ & $\lambda_{i}$ & $\theta_{i}$ & $m_{i}$ & $c_{i}$ & 0.25 \\
\hline 1 & 3 & 8 & 22 & 14 & 12 & 0.75 \\
2 & 4 & 9 & 24 & 16 & 14 & 0.30 \\
3 & 2 & 5 & 14 & 10 & 5 & 0.90 \\
4 & 5 & 11 & 11 & 17 & 17 & 0.35 \\
\hline
\end{tabular}

TABLE 2: Equilibrium strategies of innovation subjects under noncooperative conditions.

\begin{tabular}{lccc}
\hline Innovation subject & $s_{i}^{*}$ & $\pi_{i}^{*}\left(s_{i}^{*}, c_{i}\right)$ & $\pi^{*}\left(S^{*}, C\right)$ \\
\hline 1 & 0.0976 & 11.4784 \\
2 & 0.1234 & 13.5110 \\
3 & 0.1275 & 4.3937 \\
4 & 0.1517 & 16.8095 \\
\hline
\end{tabular}

TABLE 3: Equilibrium strategies of innovation subjects under collaboration.

\begin{tabular}{lccc}
\hline Innovation subject & $s_{i}^{* *}$ & $\pi^{* *}\left(S^{* *}, C\right)$ & $\pi^{* *}\left(S^{* *}, C\right)$ \\
\hline 1 & 0.6389 & 12.0293 \\
2 & 0.6194 & 14.3278 & 4.8499 \\
3 & 0.5916 & 17.5961 & 99.6471 \\
4 & 0.3536 & \\
\hline
\end{tabular}

TABLE 4: Equilibrium strategies of innovation subjects with government subsidies.

\begin{tabular}{lccc}
\hline Innovation subject & $s_{i}^{* * *}$ & $\pi_{i}^{* * *}\left(s_{i}^{* * *}, c_{i}\right)$ & $\pi^{* * *}\left(S^{* * *}, C\right)$ \\
\hline 1 & 1.6129 & 17.0757 & \\
2 & 1.5778 & 17.0669 & 128.4831 \\
3 & 1.5788 & 18.9570 & 0.9999 \\
4 & 1.5811 & 17.1587 & \\
\hline
\end{tabular}

higher than the noncooperative and cooperative situation, realizing the optimal expected overall profits of the new energy automobile innovation technology innovation value chain system. It shows that the equilibrium strategy based on government subsidies can realize the optimal expected overall profits of the new energy automobile innovation technology innovation value chain system. At the same time, it can protect the expected profits from the loss of innovation subject, realize Pareto Optimality, arouse the enthusiasm and initiative of innovation subject to participate in $R \& D$, prompting them to put more effort into it.

To illustrate the effectiveness of different strategies, this paper makes a comparison, as shown in Table 5.

Comparing the cooperation strategy without government subsidy and with government subsidy, we can know that $s_{i}^{\prime}$, $\pi_{i}^{\prime}\left(s_{i}^{\prime}, c_{i}\right)$, and $\pi_{i}^{\prime}\left(s_{i}^{\prime}, c_{i}\right)$ of the latter strategy are all better than the former. Apart from $\pi_{4}^{\prime}\left(s_{4}^{\prime}, c_{4}\right)$ of cooperation strategy 1 ( equal to 17.1587) is bigger than cooperation strategy 2 (equal to 17.5961). This result can be explained that innovative entity 4 trusts the government more and are willing to sacrifice personal profits to maximize system profits.

According to the model and case analysis, the mechanism designed in this paper can solve the problem of industrial R\&D incentive with government subsidies. Under the designed mechanism, profits are not damaged in the protection of the innovation subject, and technology innovation value chain system expects overall profits maximization. Simultaneously, it fully mobilizes the enthusiasm and initiative of innovation subject and forces them to put enough matched manpower, material resources, and financial resources into the system. At the same time, there is a reasonable level of government subsidies. At a low level, the efforts of innovation subjects will increase with the increase of subsidies, but the utility of the system is at a low level. When the government is short of funds for subsidies, the government should pay more attention to the R\&D risks of innovation subjects. For this reason, the barriers to the exchange and transmission of $\mathrm{R} \& \mathrm{D}$ information among innovation subjects can be eliminated by strengthening the guarantee of infrastructure, such as establishing the R\&D information service platform for key technologies of the new energy automobile industry. As an important part of national innovation system, science and technology intermediary institutions can reduce innovation risks and accelerate the transformation of scientific and technological achievements in the process of building the connection between innovation subjects and factor markets. The government should give full play to the role of science and technology 
TABLE 5: Comparison of the results of different strategies.

\begin{tabular}{|c|c|c|c|c|c|c|c|c|}
\hline Strategies & \multicolumn{4}{|c|}{$\begin{array}{c}\text { Cooperation strategy } 1 \text { without government } \\
\text { subsidy }\end{array}$} & \multicolumn{4}{|c|}{ Cooperation strategy 2 with government subsidy } \\
\hline Innovation subject & 1 & 2 & 3 & 4 & 1 & 2 & 3 & 4 \\
\hline$\overline{s_{i}^{\prime}}$ & 0.6389 & 0.6194 & 0.5916 & 0.3536 & 1.6129 & 1.5778 & 1.5788 & 1.5811 \\
\hline$\pi_{i}^{\prime}\left(s_{i}^{\prime}, c_{i}\right)$ & 12.0293 & 14.3278 & 4.8499 & 17.5961 & 17.0757 & 17.0669 & 18.9570 & 17.1587 \\
\hline$\pi_{i}^{\prime}\left(s_{i}^{\prime}, c_{i}\right)$ & \multicolumn{4}{|c|}{99.6471} & \multicolumn{4}{|c|}{128.4831} \\
\hline
\end{tabular}

intermediaries to provide various innovation subjects with talents, market, knowledge, and other services. However, at a higher level of government subsidies, as the government compensates some innovation subjects with a large amount of funds, it will produce moral hazard, such as opportunism, and maximize its expected interests by cheating government subsidies. Therefore, the government should establish a reasonable contract mechanism to restrain the opportunistic behavior of innovation subjects. The government should improve relevant laws and regulations and increase the punishment for violations to provide a good environment for innovative technology R\&D of new energy automobile industry. In addition, the core of scientific and technology innovation lies in talents. The government needs to increase the investment of scientific and technological personnel and supporting funds related to innovative technologies of new energy automobiles, build a reasonable training system for key technologies and scientific and technological services in the industry, and set up a reward system for scientific and technological personnel and a profits distribution system.

\section{Conclusion}

To deal with the incentive problem of key technology R\&D of new energy automobile industry, from the perspective of government subsidy, considering the risk attitude decisionmaking preference of innovation subjects, we establish a government subsidy incentive mechanism of key technology R\&D of new energy automobile industry, which is based on grey target negotiation and then exploit a case to verify the effectiveness and rationality of the mechanism. According to the model and case analysis, it can be seen that government subsidy is an effective means to solve the incentive problem of multisubject conflict of interest. At a low subsidy level, the efforts of innovation subjects will increase with the increase of subsidies, but the utility of the system is at a low level. When subsidy is insufficient, the government should pay more attention to the R\&D risks of innovation subjects. Therefore, appropriate government subsidies can protect the profits of innovation subjects are not be damaged. Appropriate government subsidies can also mobilize their enthusiasm and initiative for maximizing the profits of the whole system.

Compared with the previous research, this paper has the following advantages: (1) The government and the innovation subjects have a balance between Nash equilibrium and Shapley equilibrium state, and the constraint conditions ensure stable and effective incentive of the method. (2) Introduce the minimum cost consensus method into grey target decision-making, consider the risk attitude of government and innovation subjects, and it can show the influence mechanism of government subsidies on the innovation behavior of innovative subjects.

However, this model also has some shortcomings. For example, the innovation subjects may pay attention to each other's fairness in profits distribution, which is the next research to be carried out.

\section{Data Availability}

The data used to support the findings of this study will be considered by the corresponding author. Her e-mail: huan983405544@163.com.

\section{Ethical Approval}

The human manuscripts involving human participants, human data, or human tissue are carried out according to the Institutional Animal Care and Use Committee Guide in Merck Research Labs.

\section{Consent}

The authors affirm that human research participants provided informed consent for publication of the images. And the participant has consented to the submission of the case report to the journal.

\section{Conflicts of Interest}

The authors declare that they have no financial and personal relationships with other people or organizations that can inappropriately influence our work, there is no professional or other personal interest of any nature or kind in any product, service, and/or company that could be construed as influencing the position presented in, or the review of, the manuscript entitled. And this paper is new. This is truly our joint work which we all agree to publish in Environmental Science and Pollution Research. It has not been submitted anywhere else and is not under consideration by any other editorial office and/or conference committee.

\section{Authors' Contributions}

$\mathrm{Ru} \mathrm{He}$ and Chui-yong Zheng designed and wrote this article. Huan-huan Zhao examined the article and revised the article format. 


\section{References}

[1] B. C. Belanger, G. A. Uriano, and R. G. Kammer, "Program report - the Advanced Technology Program: a new role for NIST in accelerating the development of commercially important technologies," Journal of Research of the National Institute of Standards and Technology, vol. 96, no. 5, pp. 605-611, 1991.

[2] J.-T. Chiang, "High-technology targeting: its modes' strategies and paradigms," Technology in Society, vol. 20, no. 1, pp. 1-23, 1998.

[3] Å. Cappelen, A. Raknerud, and M. Rybalka, "The effects of $\mathrm{R} \& \mathrm{D}$ tax credits on patenting and innovations," Research Policy, vol. 41, no. 2, pp. 334-345, 2012.

[4] X. N. Ma and D. H. Gong, "R\&D game and government subsidy of strategic emerging industry commonality technology," Research on Economics and Management, vol. 1, pp. 73-78, 2014.

[5] B. Wu, P. Liu, and X. Xu, "An evolutionary analysis of lowcarbon strategies based on the government-enterprise game in the complex network context," Journal of Cleaner Production, vol. 141, pp. 168-179, 2017.

[6] G. H. Xie, Y. He, and S. F. Jin, "The impact of venture capital on the effectiveness of government subsidies in stimulating corporate innovation," Chinese Journal of Management, vol. 15, no. 9, pp. 1337-1346, 2018.

[7] H. T. Shang and X. S. Huang, "Research on the interaction effects among government subsidy, R\&D investment and innovation performance," Studies in Science of Science, vol. 36, no. 3, pp. 446-455+501, 2018.

[8] X. H. Sun, X. Guo, and J. Wang, "Government subsidy, ownership, and firms' R\&D decisions," Journal of Management Science in China, vol. 20, no. 6, pp. 18-31, 2017.

[9] A. Wu, "The signal effect of Government R\&D Subsidies in China: do ownership matter?" Technological Forecasting and Social Change, vol. 117, pp. 339-345, 2016.

[10] J. Wu, Z. L. Tian, and X. F. Long, “The impact of government subsidies on corporate innovation in strategic emerging industries," Studies in Science of Science, vol. 1, pp. 158-166, 2018.

[11] H. Peng and Y. Liu, "How government subsidies promote the growth of entrepreneurial companies in clean energy industry: an empirical study in China," Journal of Cleaner Production, vol. 188, no. 1, pp. 508-520, 2018.

[12] F. Yu, Y. Guo, K. Le-Nguyen, S. J. Barnes, and W. Zhang, "The impact of government subsidies and enterprises' $\mathrm{R} \& \mathrm{D}$ investment: a panel data study from renewable energy in China,” Energy Policy, vol. 89, pp. 106-113, 2016.

[13] B. Li, W. Chen, C. Xu, and P. Hou, "Impacts of government subsidies for environmental-friendly products in a dualchannel supply chain," Journal of Cleaner Production, vol. 171, pp. 1558-1576, 2018.

[14] J. L. Lin, "An empirical study on the impact of government $\mathrm{R} \& \mathrm{D}$ subsidies on SMEs' R\&D investment," Management World, vol. 34, no. 3, pp. 180-181, 2018.

[15] H. X. Peng and G. S. Wang, "Measurement and analysis of the effect of Chinese government innovation subsidy," The Journal of Quantitative \& Technical Economics, vol. 1, pp. 77-93, 2018.

[16] R. B. Deng and F. X. Wu, "R\&D model, technology spillovers and optimal government subsidy," Studies in Science of Science, vol. 35, no. 6, pp. 842-852, 2017.

[17] A. Söderblom, M. Samuelsson, J. Wiklund, and R. Sandberg, "Inside the black box of outcome additionality: effects of early-stage government subsidies on resource accumulation and new venture performance," Research Policy, vol. 44, no. 8, pp. 1501-1512, 2015.

[18] R. Bronzini and P. Piselli, "The impact of R\&D subsidies on firm innovation," Research Policy, vol. 45, no. 2, pp. 442-457, 2016.

[19] J. Hong, B. Feng, Y. Wu, and L. Wang, "Do government grants promote innovation efficiency in China's high-tech industries?" Technovation, vol. 57-58, pp. 4-13, 2016.

[20] D. Q. Yang and R. J. Liu, "The study on the space-time differentiation of high-tech industry R\&D subsidies in China," Studies in Science of Science, vol. 36, no. 3, pp. 435-445, 2018.

[21] J. Y. Dong, L. Gai, F. Wang, and S. P. Wan, “A new method for Atanassov's interval-valued intuitionistic fuzzy MAGDM with incomplete attribute weight information," Information Sciences: AnInternational Journal, vol. 316, pp. 329-347, 2015.

[22] J. Du and D. Ouyang, "Progress of Chinese electric vehicles industrialization in 2015: a review," Applied Energy, vol. 188, pp. 529-546, 2017.

[23] S. L. Mabit and M. Fosgerau, "Demand for alternative-fuel vehicles when registration taxes are high," Transportation Research Part D: Transport and Environment, vol. 16, no. 3, pp. 225-231, 2011.

[24] C. Jiang, Y. Zhang, M. Bu, and W. Liu, "The effectiveness of government subsidies on manufacturing innovation: evidence from the new energy vehicle industry in China," Sustainability, vol. 10, no. 6, pp. 1692-1702, 2018.

[25] Y. H. Ma and Q. Na, "The selection of government subsidy strategy under the industry-university-research cooperative innovation mode," Operations Research and Management Science, vol. 27, no. 4, pp. 191-199, 2018.

[26] X. Dai and L. Cheng, "The effect of public subsidies on corporate R\&D investment: an application of the generalized propensity score," Technological Forecasting and Social Change, vol. 90, no. 2, pp. 410-419, 2015.

[27] T. L. Zhang and J. J. Wang, "Analysis of government subsidies in the supply chain of new energy automobile industry based on Shapley value method," Soft Science, vol. 29, no. 9, pp. 54-58, 2015.

[28] Y. Zhang and C. X. Lu, "The evolutionary game analysis of the government, enterprises and consumers in the post-subsidy era of new energy vehicle," Journal of Chongqing Jianzhu University, vol. 39, no. 5, pp. 38-48, 2020.

[29] J. Z. Xu and Y. Sun, "Research on the evolutionary game of collaboration and innovation of new energy automobile industry under market mechanism and government supervision," Operations Research and Management, vol. 29, no. 5, pp. 147-155, 2020.

[30] Y. Fu and R. Piplani, "Supply-side collaboration and its value in supply chains," European Journal of Operational Research, vol. 152, no. 1, pp. 281-288, 2004.

[31] Y. Liu, "Incentive mechanism for collaborative innovation of industry-university form the benefit distribution perspective," Journal of Systems Management, vol. 25, no. 6, pp. 985-993, 2016.

[32] Y. Liu, J.-L. Du, J.-B. Yang, W.-Y. Qian, and J. Y.-L. Forrest, "An incentive mechanism for general purpose technologies R\&D based on the concept of super-conflict equilibrium: empirical evidence from nano industrial technology in China," Technological Forecasting and Social Change, vol. 147, pp. 185-197, 2019.

[33] Y. Liu, L. R. Jian, and H. H. Zhao, "Profits distribution model of university-industry collaborative innovation value chain 
based on double efforts," $R$ \& $D$ Management, vol. 27, no. 1, pp. 24-34, 2015.

[34] J. Z. Li, "Supply and diffusion model selection of generic technology," Science of Science and Management of S. \& T.vol. 32, no. 10, pp. 5-12, 2011.

[35] J. Z. Li and Q. W. Deng, "Multi-failure on the supply and diffusion system of industrial generic technology," Science of Science and Management of S. \& T.vol. 32, no. 7, pp. 5-10, 2011.

[36] Z. Gong, X. Xu, L. Li, and C. Xu, "Consensus modeling with nonlinear utility and cost constraints: a case study," Knowledge-Based Systems, vol. 88, no. C, pp. 210-222, 2015. 